\title{
"CAPACIDADES" COMO POSTULADO PARA AMPLIAR A COMUNIDADE JURÍDICA E MORAL NA PROPOSTA DE MARTHA NUSSBAUM
}

\author{
Samantha Buglione ${ }^{1}$ \\ Neide Köhler Schulte ${ }^{2}$
}

\begin{abstract}
Resumo:
Quem são os membros de uma comunidade moral e por quê? É possível responder essa pergunta de várias formas e essas formas irão navegar por diferentes concepções teóricas. O desenvolvimento das capacidades foi utilizado por autores como Amartya Sen e Martha Nussbaum no sentido de fundamentar pressupostos como liberdade e igualdade. Nessa esteira, Nussbaum usa a mesma lógica para pensar a relação entre humanos e não-humanas. A discussão sobre a proteção dos animais não-humanos, desde o seu reconhecimento como sujeitos de direitos até o dever de respeito, encontra diferentes teorias na ética prática. O presente artigo analisa a proposta de Martha Nussbaum, cujo argumento do desenvolvimento das capacidades fundamenta o reconhecimento do dever de respeito e reconhecimento dos animais não-humanos como sujeitos de direitos.
\end{abstract}

Palavras-chaves: Nussbaum. Animais não-humanos. Desenvolvimento das capacidades.

\section{Introdução}

No julgamento do habeas corpus impetrado em favor de Lili e Megh ${ }^{3}$, dois chimpanzés de nome científico Pan Troglodyte, o relator do processo, ministro Castro Meira, disse ser incabível a impetração desse instrumento jurídico em favor

\footnotetext{
1 Doutora em Ciências Humanas pelo Programa de Pós-graduação Interdisciplinar em Ciências Humanas da Universidade Federal de Santa Catarina, Mestre em Direito, Professora de ética e filosofia no curso de Administração Pública e Administração Empresarial da Universidade do Estado de Santa Catarina na Escola Superior de Administração e Gerência, Florianópolis, SC, Brasil. E-mail: buglione.s@gmail.com.

${ }^{2}$ Doutora em Design pela Pontifícia Universidade Católica do Rio de Janeiro, Rio de Janeiro, RJ, Brasil. Professora titular da Universidade do Estado de Santa Catarina, Florianópolis, SC, Brasil. Email: neideschulte@gmail.com.

${ }^{3}$ Destaca-se que o primeiro caso desta natureza, no Brasil, foi o habeas corpus em favor de "Suíça", chimpanzé também de nome científico: Pan troglodytes, que se encontra aprisionada no Parque Zoobotânico Getúlio Vargas (Jardim Zoológico), em 19 de setembro de 2005. O habeas corpus foi impetrado pelos Promotores de Justiça Heron José de Santa, Luciano Rocha Santana, Antonio Ferreira Leal Filhos, juntamente com a Associação Brasileira Terra Verde Viva, União Defensora dos animais Bicho Feliz, Associação Brasileira Protetora dos Animais, além de vários estudantes de direito.
}

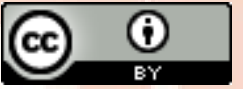


de animais não-humanos. Para ele, o habeas corpus, previsto no inciso LXVIII do artigo $5^{\circ}$ da Constituição Federal, que diz: "conceder-se-á habeas corpus sempre que alguém sofrer ou se achar ameaçado de sofrer violência ou coação em sua liberdade de locomoção, por ilegalidade ou abuso de poder", refere-se exclusivamente a humanos. A conclusão, a partir do argumento do ministro, é que os direitos fundamentais previstos na carta constitucional são humanos, portanto, os destinatários dessas prerrogativas são apenas seres da espécie humana. Ser humano torna-se categoria e condição para que alguém se torne titular de direitos fundamentais. Mas, uma condição necessária, ao invés de suficiente. A titularidade de direitos, com isso, é antropocêntrica, fazendo com que o "alguém", a que se refere 0 inciso LXVIII do artigo $5^{\circ}$, seja somente 0 humano ${ }^{4}$ e exclua automaticamente, do âmbito de proteção da norma, qualquer outro ser.

A defesa dos animais, feita pelo advogado Rubens Forte, autor do habeas corpus, fundamentou-se na tese de que os símios possuem 99\% do DNA humano e que, por essa razão biológica, deveriam, por analogia, receber o mesmo tratamento jurídico dos humanos. Na tentativa de reconhecer direitos aos não-humanos, o advogado adota a estratégia de aproximar os símios dos humanos. Isso não só limita o debate sobre os sentidos dados, histórica e moralmente, a categorias como pessoa e sujeito de direitos, mas também reforça lógicas antropocêntricas.

Ao pensar a igualdade apenas a partir da aproximação biológica com a espécie humana, o autor do habeas corpus ignora outros argumentos já desenvolvidos na ética prática. A igualdade, como um princípio prescritivo, não está na semelhança biológica entre os seres, pois, se assim fosse, negros e mulheres padeceriam do esforço em provar que se equiparam ao padrão hegemônico do "humano homem branco". Negros e mulheres foram considerados sujeitos, não porque seriam iguais biologicamente ao modelo de humano aceito, mas porque o conceito de igualdade foi aplicado de forma mais coerente: tratar seres semelhantes, em situações semelhantes, de forma semelhante (no caso dos negros e mulheres: estarem vivos, sentir, ter linguagem). É possível, ainda, afirmar que os sentidos de

\footnotetext{
${ }^{4}$ No Brasil, conforme algumas decisões judiciais não é necessário ser "humano nascido" ou "pessoa humana" para ser sujeito de um habeas corpus. Em 2003, um padre católico impetrou no Superior Tribunal de Justiça um habeas em favor de um feto anencéfalo (Habeas n. 32.129). O habeas, tecnicamente inadequado para o propósito, não só foi aceito, o pedido foi deferido. A consequência foi que a mulher não pôde interromper a gestação, conforme decisão anterior do Tribunal do Rio de Janeiro. Essa ação foi determinante para toda a discussão pública sobre anencefalia que culminou no julgamento realizado em 2012 no STF liberando a interrupção da gestação para esses casos com o argumento de que não há ser vivo em caso de anencefalia.
} 
pessoa e humano se ampliaram com o reconhecimento de mulheres e negros como sujeitos de direitos. O termo "pessoa", usado muitas vezes no direito como sinônimo de "humano", passou a incluir novos personagens, novos "alguéns", ampliando, assim, a comunidade moral no que se refere a sujeitos que deveriam ter seus interesses respeitados. Observa-se que há uma insistência em compreender de forma sinônima categorias distintas, como "humano" (configuração biológica) e "pessoa" (configuração política), e de utilizá-las arbitrariamente para justificar prescrições e ações jurídicas e morais. O fundamento de tais condutas, como a do ministro do STJ no caso dos símios, pode ser encontrado em uma razão intuitiva ${ }^{5}$, em tradições e em conceitos fundados em verdades refutáveis ${ }^{6}$. Além disso, são condutas e argumentos que põem em risco uma compreensão adequada do princípio da igualdade.

A igualdade só é um princípio válido se for universal, geral e prescritível (HARE, 1981). O que exige, portanto, critérios para além de razões relativas como raça, sexo, classe social ou espécie. Para Singer (2002), o princípio da "igual consideração de interesses semelhantes" ordena ao agente moral não agir tendo como referência exclusivamente os seus benefícios, interesses, prazeres ou satisfações. A consequência da utilização de um princípio como princípio é que a prescrição adotada para orientar as ações e decisões das quais humanos, ou determinados grupos, são diretamente beneficiados deve ser coerentemente adotada para orientar as ações e decisões em situações semelhantes, mesmo quando os humanos ou um grupo específico não sejam os principais beneficiados (FELIPE, 2008).

A questão é compreender quais critérios são necessários para compor a comunidade moral ou para entender a quem se aplica o conceito de igualdade. Peter

\footnotetext{
${ }^{5}$ Richard Hare trabalha com dois níveis de racionalidade: razão crítica e razão intuitiva. A razão crítica é um nível mais apurado, porque não se sustenta em percepções históricas, culturais, ritos familiares ou experiências pessoais como referência para condicionar a forma de observar os fenômenos ou justificar as ações, como ocorre com a razão intuitiva. A razão crítica é passível de ser compartilhada e exige uma maior atenção e avaliação, como o saber científico. Como salienta Hare, a distinção entre dois níveis de raciocínio moral não é original. Já está presente em Platão, com a distinção entre conhecimento e crença, e em Aristóteles, com a diferença entre motivação correta e sabedoria prática, virtude do caráter e do intelecto (o quê e o por quê). Cf. HARE, Richard. Moral Thinking: its Levels, Method and Point. Oxford: Clarendon Press, 1981.

${ }^{6}$ Popper (1982) propôs um critério de comprovação, que denominou falseabilidade para determinar a validez científica e sublinhou o caráter hipotético-dedutivo da ciência. Esse critério parte do pressuposto de que as verdades científicas só são científicas se passíveis de serem refutadas. O que dá seriedade à ciência não é a crença na informação, mas a possibilidade de verificação e superação de uma determinada informação. Independente das críticas possíveis a Popper, a ideia da verificação de uma tese científica contribui indiscutivelmente para a compreensão do que é ciência.
} 
Singer, por exemplo, utiliza o critério da senciência para a constituição da comunidade moral e, com isso, amplia o dever de respeito de um agente moral para com os demais seres. Para ele, todo o ser com capacidade de sentir dor e prazer é um ser que deve ter seus interesses considerados. O que define pessoa, portanto, não é a racionalidade kantiana, mas o fato de ser sujeito de interesses e preferências. A condição, para isso, é ser um ser sensível e consciente, com capacidade de sentir dor e prazer. O conceito de pessoa de Singer assemelha-se à ideia de "sujeito-de-uma-vida" de Regan (SINGER, 2002; 2004).

Tom Regan (2006) e Paul W. Taylor (1987) utilizam outros critérios. Para Regan, que trabalha com o conceito de sujeitos com valor inerente, o fato de se estar vivo é um bem em si, se for um bem para o próprio sujeito vivo, configurandose então, a vida, como um bem próprio. Ser um ser que se auto-orienta em seu viver torna um ser "sujeito-de-uma-vida" e, consequentemente, o fato de "ser vivo", não apenas "estar na vida", torna-se critério suficiente para que (o ser) tenha seus interesses protegidos e respeitados. Taylor, por sua vez, utiliza a ideia de "valor inerente" de forma similar, como a de um bem próprio, fundamento do respeito ao ser que vive e conduz a própria vida. Para Regan, o valor inerente é um dos bens que o ser (que é) "sujeito que vive a vida" tem; isso cria a exigibilidade dos interesses desse sujeito para com os outros. Para Taylor, reconhecer valor inerente dá valor ao ser, ainda que não seja vivo, e isso fundamenta o dever de respeito aos interesses desse ser, por exemplo, o dever de preservar um aglomerado rochoso milenar.

Segundo Felipe,

para a ética antropocêntrica só pode haver valor inerente em sujeitos dotados de autonomia moral, para a senciocêntrica há valor intrínseco em todas as espécies de vida nas quais se manifesta a senciência ${ }^{7}$; já a ética biocêntrica, que pressupõe apenas "o ser que vive a vida" como condição suficiente para ser sujeito de respeito, opera no reconhecimento de valor inerente a este ser (FELIPE, 2008, p. 4).

O valor inerente

não pode depender de juízos formulados por sujeitos interesseiros, nem interessados no estabelecimento do valor, pois, se o valor inerente

\footnotetext{
${ }^{7}$ Senciência significa sensibilidade e consciência ou percepção de si. A consciência é a capacidade de se perceber no mundo, um conceito mais amplo que o sentido de racionalidade nos moldes humanos.
}

R. Inter. Interdisc. INTERthesis, Florianópolis, v.10, n.1, p. 212-236, Jan./Jul. 2013 
depender dos interesses de sujeitos racionais, corre o risco de ser pensado simplesmente apenas como mais um tipo de valor instrumental (FELIPE, 2008, p. 4).

O valor inerente, portanto, é o valor do "ser que vive" e isso independe da capacidade de percepção do ser sobre si mesmo.

Compreender os animais não-humanos como sujeitos de direitos exige não apenas ampliar a comunidade moral, mas (re)pensar as categorias jurídicas de "sujeito de direitos", "direitos subjetivos" e "personalidade jurídica", o que também requer uma análise para além de paradigmas antropocêntricos e androcêntricos. Exige, ainda, que os sentidos de pessoa, humano e destinatário de uma norma jurídica (que opera tanto através da proteção, quanto do chamamento à responsabilidade do sujeito por determinada ação), sejam conceituados de forma a evitar relativismos e privilégios que criem incoerências ao próprio sistema jurídico.

Argumenta-se, neste artigo, que os postulados e princípios jurídicos são capazes de abarcar humanos e não-humanos como sujeitos de direito com direitos subjetivos $^{8}$. A decisão do STJ, trazida no exemplo, não apenas compreende as categorias pessoa e humano como sinônimos, mas não se preocupa em observar os sentidos e consequências decorrentes dos postulados e princípios aos quais está o STJ subordinado. A interpretação feita pelo STJ sobre o fato e sobre a norma jurídica é, pela análise de seus argumentos, expressão ou sintoma de um ethos cujo sentido decorre de lógicas discriminatórias, fundadas no racismo, machismo, classismo e, no caso, especismo.

\footnotetext{
${ }^{8} \mathrm{O}$ sentido de direito subjetivo tradicionalmente relaciona-se à legitimidade para agir, vincula-se a uma faculdade de agir (faculta agendi), um querer agir, que opera na garantia de um interesse (Teoria do Interesse de Ihering), ou, ainda, como poder da vontade, garantido pelo ordenamento jurídico (Teoria da Vontade de Windscheid). O importante, porém, é que o direito subjetivo opera com uma dupla característica, ele tanto sujeita alguém (um terceiro) - que é direito subjetivo potestativo, quanto permite exigir uma prestação, um dever relacionado ao direito posto - o direito subjetivo a uma prestação. Para uma ou outra situação, é condição a existência, individual, de um ser capaz de viver a vida e não um ser com a capacidade reivindicatória, eis que essa pode ser suprida a partir da tutela. O direito subjetivo é subjetivo porque as permissões que o constituem são próprias do ser que as possuem. Os direitos subjetivos podem, então, ser: 1. "potestativos", e, 2. "prestativos", direitos que têm por finalidade bens da vida, ou seja, conseguir-se algo, mediante uma prestação. Os direitos potestativos competem a alguém influir, através da declaração da vontade, sobre a situação jurídica. Ele não se confunde com a capacidade jurídica, pois está atrelado às condições do fato, por exemplo, somente pessoas casadas podem pedir separação, somente supostos filhos podem pedir investigação de paternidade. Tais direitos criam um estado de sujeição para a outra pessoa. Sujeição é a situação daquele que, independentemente da sua vontade, ou mesmo contra sua vontade, sofre uma alteração na sua situação jurídica, por força do exercício de um daqueles poderes atribuídos a outra pessoa. A sujeição dispensa o concurso da vontade do sujeito. Cf. CHIOVENDA, Giuseppe. Instituições de direito processual civil. v. I. Tradução J. Guimarães Menegale. 2. ed. São Paulo: Saraiva, 1965.
} 
Diferentes autores ${ }^{9}$ sugerem parâmetros para estruturar o conceito de sujeito de direitos. Todos eles, em alguma medida, vão fazer uso de postulados para fundamentar, ao fim, suas teses. É assim com a norma fundamental de Hans Kelsen e com o conceito de dignidade humana de Kant ${ }^{10}$.

Neste artigo trabalhamos com a tese de Martha Nussbaum (2004), feminista e filósofa do direito, que postula o "desenvolvimento das capacidades" como o critério para se reconhecer "alguém" como parte da comunidade jurídica. A categoria do "desenvolvimento das capacidades" já foi usada em outros contextos. Amartya Sen (2000), economista indiano, ganhador do Nobel de Economia, que criou o Índice de Desenvolvimento Humano (IDH) a partir da ideia de desenvolvimento como liberdade. A base da sua teoria era o direito dos sujeitos de desenvolverem suas capacidades, o que, segundo Sem, pressupõe liberdade; o ponto central de seu trabalho, portanto, é a consideração da liberdade como condição para o desenvolvimento das capacidades dos sujeitos. Martha Nussbaum, na corrente da proposta de Sen, utiliza o conceito de desenvolvimento das capacidades para pensar os direitos e a igualdade para animais não-humanos. Nossa análise vai no sentido de verificar as contribuições e limitações da proposta de Nussbaum no que se refere à ampliação da comunidade jurídica e à compreensão dos animais nãohumanos como sujeitos de direito. Para desenvolver esta análise usamos a literatura

\footnotetext{
${ }^{9}$ É importante observar que há vasta literatura nacional sobre o tema de direito dos animais e autores brasileiros de peso tais quais Laerte Levai, Danielle Rodrigues, Daniel Braga, Heron Gordilho e outros. Destaca-se, ainda, a Revista Brasileira de Direito Animal pela sua contribuição e por ser a primeira revista do gênero em língua latina. Como este artigo não se propõe a uma revisão bibliográfica, mas a estudar a tese de Nussbaum selecionamos alguns autores, na sua maioria, estrangeiros.

${ }^{10}$ Kant apregoa que a dignidade humana está no ato de autonomia do sujeito em dar a si mesmo sua lei moral. Ele define pessoa, portanto, a partir de uma racionalidade modelo. Para além disso, a dignidade está no dever do agente em reconhecer as pessoas como fim em si mesmo, conforme a segunda formulação do imperativo categórico. Cf. KANT, Emanuel. Resposta à pergunta: O que é o esclarecimento? In: KANT, Emanuel. À paz perpétua e outros opúsculos. Tradução Arthur Morão. Lisboa: Edições 70, 1995. Kelsen, ao construir sua teoria pura do direito, ou seja, do direito como ciência com fundamento próprio, não vinculado nem à sociologia, nem à filosofia, trata de estruturar um sistema cuja base seja o próprio direito, no caso, uma norma jurídica. A legitimidade do direito estaria não em razões metafísicas ou sociológicas, mas nele mesmo a partir de um procedimento que nada mais é do que uma norma. O desafio de Kelsen, porém, é dar fundamento último a seu sistema. Em outras palavras, dar conta de responder à pergunta sobre o que fundamenta a norma fundadora de um sistema jurídico sem remeter-se à vontade do povo ou à força (razão social) ou a deus ou à natureza (razão metafísica). Kelsen cria a norma fundamental, que nada mais é do que um postulado, dando condições de existência a uma prescrição normativa, no caso, a escolha individual dos sujeitos em "dar a si mesmo a norma jurídica". O cumprimento da norma jurídica, nesse sentido, é um ato de liberdade porque é possível não só descumpri-la, como alterá-la, através do procedimento normativo. Kelsen, ao final, estrutura seu sistema a partir da ideia kantiana de autonomia e não de heteronomia. Cf. KELSEN, Hans. Teoria Pura do Direito. Tradução João Baptista Machado. $6^{a}$ ed. São Paulo: Martins Fontes, 1998.
} 
que dialoga diretamente com Nussbaum e os autores paradigmáticos no tema de reconhecimento de dever de cuidado com animais não-humanos ou de direitos dos animais.

\section{Postulados e Princípios}

Martha Nussbaum pensa o desenvolvimento das capacidades como um critério para reconhecer os interesses de animais não-humanos, interesses com obrigatoriedade de reconhecimento e respeito porque trata-se do interesse de sujeitos de direitos. A proposta de Nussbaum, de incluir as capacidades como um critério que venha a orientar a ação (prescrição), é um exemplo de postulado, uma proposição que se admite ou que se pede que seja admitida a fim de tornar possível uma demonstração, uma tese ou um procedimento (ABBAGNANO, 2004), ou seja, uma proposição que representa, do ponto de vista do assentimento, a característica de poder ser tomada como fundamento da demonstração (LALANDE, 1999).

O postulado relaciona-se tanto com os axiomas quanto com as hipóteses. A diferença, entretanto, é que os axiomas, segundo Aristóteles "são por si mesmos evidentes" (ABBAGNANO, 2004, p. 184), e as hipóteses, demonstráveis. Já um postulado é uma proposta, uma ideia ou uma afirmação que não se tem qualquer condição de provar, experimentar ou verificar empiricamente. Não sendo algo verificável empiricamente, tampouco passível de experimento, não é possível afirmar a possibilidade de sua existência (hipótese), nem sua realidade (evidência). Os postulados são, pois, a priori, quer dizer, não verificáveis. Apesar disso, eles dão condição de possibilidade para a criação de prescrições, sejam elas morais, éticas ou jurídicas.

Um postulado, apesar de não ser um axioma, no sentido original da proposta, é a expressão de um valor (LALANDE, 1999), acordada e decorrente de um processo argumentativo ou de atos declaratórios, podendo fundamentar-se em crenças pessoais, em acordos políticos públicos ou privados ou, até mesmo, na metafísica, como algo proveniente de deus ou da natureza. Mas, em qualquer uma dessas alternativas, só há diferença na forma ou na fonte, em face da impossibilidade de prova ou experimento em relação à afirmação. Resta, por fim, apenas um exercício argumentativo visando à coesão e à comunhão de ideias. Em outras palavras, há necessidade de coerência na aplicação dos princípios, caso 
contrário perdem-se, tanto os objetivos visados nos princípios, quanto os valores a serem protegidos, direta ou indiretamente, nos postulados presentes.

As declarações de direito, por exemplo, são postulados declaratórios. Mesmo os que advogam razões metafísicas para fundamentar o direito, como deus ou a natureza (direito natural), não conseguem dar prova ou verificar seus fundamentos, o que permite concluir que a razão final para se considerar um direito e um sujeito de direito é, em "ultima ratio", um ato de fé.

A afirmação: a "vida humana tem dignidade" é um postulado que fundamenta a prescrição de "respeitar a vida humana". Essa prescrição, por sua vez, é um princípio, tanto ético quanto jurídico. Um princípio é uma prescrição de dever que, para ser princípio, precisa ser universal, geral e prescritivamente aplicável (BENTHAM, 1984; HARE, 1981). Se isso não ocorre, a prescrição é apenas uma estratégia retórica e arbitrária para a manutenção de privilégios de alguns sobre outros, ou seja, da dominação. Maurizio Lazzarato (2000), ao falar de Biopolítica, explica que nos estados de dominação as relações assimétricas tornam-se cristalizadas e se perde a liberdade, a fluidez e a reversibilidade. Há, portanto, diferença entre relações de poder e estados de dominação. Nas relações de poder as pessoas interagem e se influenciam, já nos estados de dominação um dos personagens é totalmente ignorado como sujeito - ele torna-se coisa, propriedade, "ser a serviço de".

A falta de coerência na aplicação de um princípio, que significa sua incidência apenas para alguns sujeitos por razões de preferência ou interesse, permite questionar em que medida a prescrição é de fato um princípio ${ }^{11}$. O critério, portanto, para a realização ou existência de um princípio, não está em fatores contingentes ou características relativas, como atributos decorrentes da classe social, status público, inteligência ou cor da pele, mas na igual aplicação da prescrição diante de situações semelhantes, o que independe das características do sujeito, mas apenas da sua situação e contexto. Trata-se, portanto, de considerar, na mesma medida, os diferentes interesses de sujeitos singulares. Essa é a base da proposta de igualdade de Singer (2002). Para ele o preceito básico de respeito à igualdade não requer

\footnotetext{
${ }^{11}$ Por exemplo, na questão da autonomia reprodutiva feminina, isso é muito significativo, quando, por questões morais e econômicas (e não éticas) a autonomia da vontade é alienada do sujeito. Quando um princípio, que é uma prescrição, como a de gerenciar a reprodução de forma autônoma, incide sobre alguns sujeitos por razões de classe ou deixa de incidir em outros por razões de raça/etnia, o que temos são incoerências na aplicação do princípio, ou seja, falta-lhes universalidade, generalidade e imparcialidade.
} 
tratamento igual ou idêntico, mas sim igual consideração aos interesses semelhantes (como integridade física, estar vivo, não viver confinado), o que implica, muitas vezes, um tratamento diferenciado, mas que garanta um mesmo resultado considerando a semelhança do interesse.

A afirmação de que postulados e princípios do direito permitem incluir nãohumanos fundamenta-se no fato de que o sujeito passivo da ação do outro, no caso o sujeito de direitos, destinatário da ação ou da consequência da ação, não precisa ser humano, como é o caso das pessoas jurídicas. Precisa, simplesmente, estar em uma situação na qual a previsão de proteção sobre si exista. Isso significa, ainda, que, no direito, não há a exigência de que a pessoa seja, ao mesmo tempo e nas mesmas condições, autor e destinatário de uma ação, porque há diferentes situações de sujeitos incapazes para atos autônomos que, nem por isso, são excluídos de proteção ou da condição de sujeitos de direito, por exemplo, crianças e pessoas com deficiência mental. O direito subjetivo vincula-se ao sentido de pessoa que, por sua vez, é uma categoria política e mutável. Com isso, o caráter universal para aplicação da prescrição jurídica (dado norma de princípio) não é o conceito de pessoa, mas a situação na qual o ser que vive a vida se encontra. Esse caráter, que não decorre do atributo ou característica do sujeito, pode ser, na proposta de Nussbaum, a garantia do desenvolvimento das capacidades dos indivíduos, algo presente tanto em humanos quanto em não-humanos e em ecossistemas naturais.

\section{Animais não-humanos como sujeitos de direito: o ponto de partida de Nussbaum}

O artigo, Beyond "Compassion and Humanity": Justice for Nonhuman Animals" (Além da "compaixão e humanidade": Justiça para animais não-humanos) de Martha Nussbaum ${ }^{12}$, tem como objeto o discurso sobre o sujeito de direito e a ideia de justiça. Para a autora, "não há qualquer razão óbvia pela qual noções básicas de justiça, titularidade e direito não possam ser estendidas para além da espécie humana". A possibilidade dessa extensão, do ponto de vista da teoria do direito, já encontra precedente em decisões judiciais. Um bom exemplo é o caso

${ }^{12}$ NUSSBAUM, Martha. Beyond "compassion and humanity": Justice for Nonhuman Animals. In: . Animal Rights: Current Debates and New Direction. Oxford, 2004.

R. Inter. Interdisc. INTERthesis, Florianópolis, v.10, n.1, p. 212-236, Jan./Jul. 2013 
Nair v. Union of India, julgado pela Suprema Corte de Kerala ${ }^{13}$, na Índia, citado por Nussbaum, que reconhece direitos fundamentais, como dignidade, aos nãohumanos.

A autora opta por pensar o tema dos animais não-humanos não a partir da senciência, um argumento vinculado à compaixão e humanidade, não sendo, para ela a melhor referência para provocar e impor ao agente moral deveres de respeito em relação a animais não-humanos. O caminho escolhido por Nussbaum é o do discurso jurídico, a partir de uma crítica à interpretação hegemônica da teoria do contrato social. Para a jurista, a senciência, e, por consequência, o dever de compaixão e a humanidade, não seria o melhor caminho, porque esse dever está fora do contrato social por ser, na sua interpretação, uma crença ${ }^{14}$. A argumentação eleita pela autora sustenta-se na tese do "desenvolvimento das capacidades", que permite elaborar princípios políticos fundamentais, pois ela proporciona uma melhor orientação teórica para se pensar questões de justiça e de direitos básicos. Dessa forma, questões como a do habeas corpus para os símios terá como fundamento o direito ao desenvolvimento das capacidades e não debates sobre semelhanças biológicas ou justiça.

Nussbaum inicia sua proposta desconstruindo duas correntes da teoria moderna de justiça e do conceito de sujeito de direitos. A primeira, a teoria da proteção dos não-humanos, presente em Kant. A segunda, a da personalidade moral, de Rawls. Nussbaum (2004) também tece críticas ao utilitarismo, apesar de reconhecê-lo como a teoria que mais contribui para a proteção dos animais nãohumanos.

Em relação à teoria kantiana, Nussbaum aborda dois pontos essenciais para justificar sua tese de que ela não contribui para a construção de uma teoria de direitos dos animais. A visão kantiana sobre os animais não-humanos não é promissora, tanto porque os deveres de respeito impostos são apenas deveres

\footnotetext{
${ }^{13}$ Kerala é um Estado da Índia que se destaca por ações de respeito aos interesses dos sujeitos historicamente excluídos. Quando a China implementou a política do filho único, Kerala passou a investir em acesso à saúde e educação. O resultado foi que, dez anos depois, os índices de filhos por mulher haviam caído mais em Kerala do que nos estados vizinhos, na China (BUGLIONE, 2010).

${ }_{14}$ Nussbaum cita uma passagem de Uma teoria da justiça, de Rawls: Certainly it is wrong to be cruel to animals... The capacity for feelings of pleasure and pain and for the forms of life of which animals are capable clearly impose duties of compassion and humanity in their case. I shall not attempt to explain these considered beliefs. They are outside the scope of the theory of justice, and it does not seem possible to extend the contract doctrine so as to include them in a natural way. Apud NUSSBAUM, Op. cit., Prefácio.
} 
indiretos para com a humanidade, tendo-se, assim, uma razão de respeito antropocêntrica, quanto pelo fato de que, para Kant, é impossível conceber que seres sem autoconsciência, no modelo humano, ou capacidade de reciprocidade moral, possam ser objeto do dever direto de proteção, logo, de obrigação moral de um terceiro para com eles. Para Kant, a razão de respeito se dá porque um tratamento cruel aos seres não-humanos reforça tendências para agir de modo semelhante para com os humanos. Para Kant, só há deveres indiretos em relação aos não-humanos, porque o dever decorre do valor de dignidade do sujeito que age e não de um valor moral presente no sujeito que sofre ação (se esse fosse o caso, haveria um dever direto).

A concepção de sujeito moral de Rawls, apesar de, diferentemente de Kant, reconhecer deveres morais diretos ${ }^{15}$ para com os animais não-humanos, concebe esses deveres como deveres de compaixão e humanidade, situados no âmbito da concepção privada de bem e das virtudes, não no âmbito da teoria política pública de justiça. Para Rawls, os animais não-humanos não são nem propriedade dos humanos, no caso um bem a ser distribuído, nem um sujeito moral.

A explicação dada por Nussbaum para essa perspectiva de Rawls é que ele opera com o sentido kantiano de pessoa, ou seja, um conceito anglo-saxão que concebe a pessoa como um agente e um agente que só o é por ter capacidade de ação consciente e racional, fundada na vontade livre. Nussbaum observa, ainda, que a crueldade e opressão são temas que levantam questões de justiça, independentemente de se tratarem de humanos ou não-humanos e calcar o dever nos sentimentos de compaixão e humanidade desvia a atenção sobre o responsável pela crueldade e violência. Nussbaum explica que o sentimento de compaixão envolve o pensamento de que uma outra criatura está sofrendo muito e que não tem culpa por isso. Esse sentimento não envolve a ideia de que alguém é culpado pelo sofrimento. A compaixão pode se dar tanto pela vítima de um crime quanto por alguém que está morrendo de uma doença. Em ambos os casos, o que causa o

\footnotetext{
${ }^{15}$ Para o contratualismo, a moral consiste em um conjunto de exigências mútuas para pessoas livres, ou em certo sentido autônomas e iguais. Diferentemente de Kant, que procura fundar a moralidade em um conceito de dever racional, as éticas contratualistas não nos comprometem com um conceito específico de razão que demanda ser justificado, mas sim, vincula-a ao agir. Rawls, nessa esteira, assume como tarefa conciliar a liberdade com a igualdade e os deveres morais com a justiça. Para Rawls, o dever se vincula não à razão num sentido absoluto ou direto, como em Kant, mas a uma forma de racionalidade. Rawls estabelece, dessa forma, que o dever moral está vinculado ao justo. Se o dever está relacionado à racionalidade e essa é uma ferramenta para a realização do justo, a ação dos humanos em relação aos outros animais deve manter-se na esteira do respeito à igualdade.
} 
sofrimento não é relevante. A autora propõe adicionar ao dever de compaixão a ideia, que segundo ela seria aceita por Rawls, de que "é errado causar sofrimento aos animais", isto é, o dever de compaixão não é apenas um dever de ter compaixão, mas sim um dever que é resultado da compaixão de alguém que se abstém de atos que causam o sofrimento (NUSSBAUM, 2004, p. 302).

Considerando que a justiça pode ser compreendida como um campo que condena a lesão causada a um sujeito pelo ato de um terceiro, os animais nãohumanos devem estar contemplados na teoria da justiça mesmo não se adequando ao modelo kantiano de sujeito moral. A consequência é a imediata extensão dos direitos fundamentais aos não-humanos, já que a esfera da justiça é a esfera dos direitos fundamentais (NUSSBAUM, 2004).

Para Nussbaum, entre os méritos dos utilitaristas está o de não cometer o erro de confundir aquele "que elabora os princípios de justiça" com aquele que "recebe os benefícios dos princípios de justiça", ela destaca o problema do consequencialismo e do hedonismo (NUSSBAUM, 2004, p. 303). Para ela, o consequencialismo, que permite ajustar a conta de bem-estar, ou do bem, não admite muitas coisas importantes como bens plurais e heterogêneos, ou, ainda, a proteção dos direitos. Medir os princípios da justiça pelo resultado que produzem, a partir de uma somatória utilitarista, ou seja, de um compromisso utilitário de agregação de prazeres, necessita, não apenas somar os bens relevantes, mas também medi-los e pensá-los de outra forma. Para ela, o bem-estar de alguns, mesmo da sociedade, não nos leva a violar um indivíduo ou permitir sua desvantagem. Pode-se, por exemplo, insistir que cada pessoa tenha um direito imprescritivel de superar um limite sobre certos bens essenciais, em outras palavras, o direito de desenvolver as próprias capacidades.

O problema do hedonismo (Bentham) e da satisfação de preferência (Singer) ocorre porque o "prazer" é uma noção notoriamente elusiva, uma sensação única, variando apenas em intensidade e duração ou, ainda, trata-se de coisas (prazeres) distintas, pessoais e contingentes, portanto, qualitativamente diferentes. Com isso, Nussbaum afirma que todos os pontos de vista utilitaristas são vulneráveis quando da aplicação do cálculo hedonista ${ }^{16}$.

${ }^{16}$ Nussbaum parece não incluir o pensamento de Stuart Mill sobre prazeres mais e menos elevados. Se o hedonismo utilitarista fosse pensado pela perspectiva de Mill o sentido contingente, argumentado por ela, poderia ser questionado. 
É por conta dessas observações que Nussbaum (2004) defende que alguns temas, o de "ser contra a escravatura", por exemplo, são melhor tratados na teoria da justiça do que a partir de um cálculo empírico do total ou da média de bem-estar, ou, dos argumentos kantianos de pessoa e dignidade. Por essa razão, ela propõe e insiste em abordar o respeito aos não-humanos a partir da teoria da justiça, ou seja, dos direitos fundamentais.

\section{O postulado do "desenvolvimento das capacidades": animais não-humanos} são sujeitos de direito com dignidade

Atualmente, a abordagem do "desenvolvimento das capacidades" se dá a partir do conceito de dignidade e de vida digna de humanos, que podem ser compreendidos, concomitantemente, como categorias de valor inerente (dignidade) e de valor intrínseco (vida digna) ${ }^{17}$ ou, de forma mais simplificada, como direito à vida e direito à qualidade de vida. Nussbaum propõe ir além do critério antropocêntrico, porque, para ela, a abordagem do desenvolvimento das capacidades pode ser estendida e, com isso, fornece uma base - para ela, a mais adequada -, para a configuração dos direitos dos animais não-humanos. Ela parte da ideia de que para compreender os sujeitos de uma vida digna é preciso dimensionar dois fatores: necessidades profundas e habilidades, que acabam sendo características presentes, tanto em humanos, quanto em não-humanos. Por isso, ela afirma que, a partir da proposta das capacidades, elementos como autonomia ou prazer tornam-se dispensáveis. A abordagem proposta por Nussbaum (2004) é uma alternativa às visões contratualista e utilitarista, pois permite melhores resultados.

O desenvolvimento das capacidades, portanto, seria o postulado capaz de fundamentar os direitos de animais não-humanos e de ecossistemas naturais e, consequentemente, a razão de se dever respeito a eles. Com isso, os não-humanos passam a integrar, como personagens, a teoria de justiça. O foco da autora, ou seja, o "ser" objeto da sua teoria de desenvolvimento das capacidades, é a criatura individual e não a espécie, eis que a abordagem das capacidades não atribui qualquer importância ao aumento da população de indivíduos de uma espécie. Seu foco é o bem-estar dos indivíduos existentes e o dano causado a eles. Quem sofre é

17 Sobre valor inerente e valor intrínseco ver Felipe (2006).

R. Inter. Interdisc. INTERthesis, Florianópolis, v.10, n.1, p. 212-236, Jan./Jul. 2013 
o indivíduo, não a espécie, pois essa é apenas uma classificação de determinados indivíduos.

A razão para defender que os não-humanos tenham direitos próprios e inerentes (ou direitos subjetivos, em um jargão mais jurídico) é que isso garante a ação de exigir (exigibilidade) respeito aos interesses do sujeito de direitos, através de um guardião legítimo, mesmo que o sujeito não tenha capacidade reivindicatória, tal qual ocorre com crianças ou com pessoas sem capacidade civil. Não apenas a sanção caracteriza as prescrições jurídicas (ela está presente em outros campos prescritivos, como a moral e a ética), a exigibilidade é o diferencial que torna os direitos subjetivos ferramentas políticas para a garantia de interesses.

Nussbaum vai ao encontro de autores como Paul Taylor - apesar de não citálo - quando aborda alguns pressupostos da sua proposta, por exemplo, quando se refere que a abordagem das capacidades encontra significado ético no desenvolvimento (ou florescimento) de capacidades inatas. As diferentes formas de vida, que têm capacidades mais complexas a serem prejudicadas, tendem a sofrer mais e sofrer diferentemente os danos. As singularidades na forma de "ser" e "viver a vida" são relevantes, "não porque agregam às diferentes espécies um valor diferencial, mas porque o tipo e grau de dano que uma criatura pode sofrer varia conforme sua forma de vida" (NUSSBAUM, 2004, p. 309). A singularidade, neste caso, não serve para hierarquizar ou agregar mais, ou menos, valor a um sujeito, mas apenas para ajudar a dimensionar maiores ou menores danos ou privações sofridos. O exemplo dado pela autora é o do chimpanzé que não sofre por não ter direito a voto, mas, uma pessoa humana sem esse direito terá, invariavelmente, parte de suas capacidades, no caso a de participação política, limitada e violada.

Apesar desse argumento, Nussbaum apresenta resquícios de uma hierarquia especista quando admite fazer uso da senciência como critério limítrofe para pensar alguns temas e seres como membros da comunidade moral e jurídica e, por consequência, de interesse da justiça. A senciência, aqui, parece ir além da dor e prazer, mas ela traz elementos como a percepção do trágico. Para ela, a partir da senciência, a morte de uma esponja não parece ser uma questão de justiça, diferentemente da morte de um gorila. Contudo, ela não oferece maiores justificativas. Parece haver uma contradição ou algum nó não desfeito. Ao mesmo tempo em que ela afirma que são "as capacidades da criatura individual" que contribuem para o argumento de proteção dos animais não-humanos, sem 
hierarquias valorativas, ela dá margem para o uso de animais em pesquisa. De forma arbitrária alguns seres vivos tornam-se tema da justiça e outros não. Nesse momento ela aceita que o pertencimento a uma espécie, à humana, por exemplo, tem algum tipo de relevância quando se pensa as capacidades inatas de um ser humano. Mesmo não considerando a espécie como um critério necessário, mas relevante, ela admite comparar crianças a chimpanzés. Diferentemente de um chimpanzé, afirma, a vida de uma criança é trágica e isso deve ser considerado. Nesse sentido, ela parece se colocar, talvez não propositadamente, na condição de bem-estarista, quando, explicitamente, afirma não ser a favor de parar com todo o tipo de investigação científica que use animais não-humanos. Nussbaum é uma filósofa do direito. Isso é relevante porque uma tese para entender essa sua posição pode estar no principio jurídico da proporcionalidade. Como estudiosa de Aristóteles e, por consequência, da ideia de prudência jurídica, a concepção de funções naturais dos seres e o tratamento diferenciado a partir delas é um parâmetro importante. Aristóteles compõe a igualdade a partir da existência de diferenças inatas e funções a serem cumpridas por cada um. O critério da distribuição da justiça, portanto, depende da função de cada um na polis. Uma função deliberada, ou fundamentada, na physis, logo, na ordem do cosmos. O principio da proporcionalidade se aproxima do sentido de prudência jurídica na qual cada caso deve ser analisado de forma particular considerando estes dois elementos: a função e a ordem do cosmos. A justiça é feita quando há harmonia e a harmonia existe quando cada um cumpre o seu dever. Aí haverá eudaimonia. Talvez seja neste ponto que repouse a razão da autora em afirmar não ser a favor de parar com todo o tipo de investigação cientifica que use animais não-humanos. Diante de um conflito legítimo de interesses iguais, uma ideia pré-determinada de funções, seria o critério determinante para considerar uma demanda mais relevante do que outra. Afinal, segundo ela, há tragédia na vida de uma criança, diferentemente da de um chimpanzé. A fragilidade do seu argumento é que ele cria uma cadeia de exceções fundada em uma lógica antropocêntrica. O critério universal, do desenvolvimento das capacidades, pode ser relativizado diante de um conflito de interesses. E o critério de "desempate" será, ao final, aquele pensado a partir de um olhar antropocêntrico.

Para Nussbaum (2004), as capacidades são elementos inerentes ao sujeito que vive, mas que se cruzam e se sobrepõem em relação ao próprio sujeito e aos 
outros. Um chimpanzé pode, por exemplo, ter mais capacidade de empatia e pensamento do que um bebê ou uma criança mais velha autista. Outras capacidades, largamente espalhadas na natureza, não fazem parte, nem de perto, do rol de capacidades inatas dos membros da espécie humana, como voar, reproduzir-se de forma autônoma, regenerar-se ao ponto de ter membros amputados restabelecidos, ter visão, olfato ou audição que permitam circular com desenvoltura em ambientes diversos, ou mesmo, fazer fotossíntese. Diante dessa diversidade de capacidades singulares, Nussbaum propõe começar avaliando as competências inatas dos seres humanos. A razão para isso pode ser porque muitas coisas presentes na vida humana servem de referencial para pensar seres de outra espécie, por serem características passíveis de universalização. Isso não significa, porém, como alerta a própria autora, romantizar a natureza ou incidir na falácia naturalista (apesar dela não fazer explicitamente referência a Moore), mas, apenas, ter a singularidade do ser que vive a vida, seja ela bios ou zoe, como referência.

Uma pergunta que surge, ao ler os argumentos de Nussbaum, é se ela não dá margem para que a potencialidade, o vir a ser, torne-se a condição para o direito subjetivo. A proteção defendida por ela é para o ser com condições de desenvolver algo inato, ou seja, algo da sua própria natureza. Pássaros devem ter garantido o direito de voar, porque voar faz parte das suas capacidades inatas, mesmo que, por alguma contingência, não consigam voar efetivamente. Minhocas têm o direito de se moverem livremente no solo, porque isso é da sua natureza. Humanos, por sua vez, devem ter o direito a uma organicidade saudável, como também, ao desenvolvimento de suas capacidades políticas. Parece, assim, que o direito se firma no que pode ser e não sobre o que é. É na ideia prévia sobre as capacidades inatas de um ser e não no ser em si, que se fundamenta o direito. O direito de desenvolver as capacidades parece querer garantir uma potência possível, que, necessariamente, pode nunca acontecer e, mais, que talvez não seja do interesse do sujeito.

Nussbaum apresenta alguns outros critérios para pensar as dinâmicas de reconhecimento de direitos e de respeito ao desenvolvimento das capacidades. Ela deixa claro, por exemplo, que o respeito pela natureza implica não apenas não fazer mal, mas também cria prescrições "cuidadosas" sobre o que poderiam ser as metas plausíveis de cuidado. Apesar dela não definir qual o parâmetro para pensar o que são essas metas, ou mesmo a ideia de cuidado, ela destaca o dever humano de 
restaurar ${ }^{18}$ ou considerar a ação que afete os habitats de animais não-humanos e ecossistemas naturais. Essa consideração faz parte do direito que os diferentes seres têm de desenvolver suas capacidades, gerando, consequentemente, um dever de respeito, de proteção, de não interferência e de restauração. Como afirma Nussbaum, "o animal, como a criança, vai reter certos direitos dos quais é titular, independentemente do que o seu guardião humano pensa. Ele não é apenas objeto para uso e controle dos seres humanos" (NUSSBAUM, 2004, p. 313). Resta saber se o direito existe, mesmo que o ser jamais tenha condições de vir a ser, no caso, de desenvolver a capacidade. E mais, em que medida os testes em animais não é o puro exercício do controle humano? Nussbaum não responde a esta pergunta.

Conforme sua proposta inicial, de ir além da abordagem antropocêntrica do desenvolvimento das capacidades, estendendo-a para não-humanos, e, com isso, ter uma série de princípios políticos básicos e mapeados que venham a orientar a legislação e a política pública, a autora desenvolve uma lista na qual conceitua as capacidades humanas que considera centrais, e desenvolve um parâmetro para os não-humanos. A lista de Nussbaum, que não é taxativa, deve ficar em aberto e sujeita à suplementação ou à supressão. Atualmente, a lista tem dez itens, e deve ser pensada, como ela sugere, como uma sistematização de normas de princípios.

\section{Fundamentando direitos para não-humanos: princípios básicos}

\section{Direito à Vida}

O ser humano deve ter assegurado o direito de viver até o fim da sua vida, de forma que essa vida não Ihe seja tirada prematuramente e valha a pena ser vivida. Os não-humanos, por sua vez, a partir da abordagem das capacidades, têm direito de continuar a sua vida, quer tenham, ou não, interesse consciente nisso. Todos os animais sensíveis têm um direito seguro contra a matança gratuita. Matar, por luxo ou esporte, é prática condenável. Por outro lado, o assassinato piedoso, como ocorre na eutanásia, ou quando do conflito de interesses, como no caso de uso de animais em pesquisa, deve ser ponderado.

${ }^{18}$ Essa ideia é muito semelhante à proposta da justiça restitutiva de Paul Taylor (1987), porém, Nussbaum não faz referência a ele em seu texto. 


\section{Saúde corporal}

Ao ser humano é garantido, do ponto de vista da prescrição jurídica, ter boas condições de saúde, incluindo a saúde reprodutiva, nutrição e abrigo adequados. Um dos direitos centrais dos animais não-humanos é o à vida saudável. Quando os animais estão diretamente sob controle humano é claro e fácil perceber as políticas implicadas, como a proibição de maus-tratos e condenação da negligência; a proibição do confinamento dos animais e dos maus-tratos na indústria de carne e peles; a proibição de tratamento cruel dos animais domésticos, dos que trabalham em circo, ou estão em zoológicos e aquários. A autora não propõe a abolição do uso de animais, apenas a garantia do seu bem-estar e o fim da assimetria - no que se refere à previsão de proteção - entre os que estão confinados para alimento humano e os que, por outro lado, estão confinados em zoológicos.

\section{Integridade física}

Todo ser humano tem direito de poder se mover livremente, de ser protegido contra a agressão violenta, nela incluído o abuso sexual e a violência doméstica, tendo, ainda, a oportunidade de satisfação sexual e escolha reprodutiva. De acordo com a abordagem das capacidades, os animais não-humanos têm direitos diretos contra a violação de sua integridade física e outras formas prejudiciais de tratamento, independentemente de o tratamento ser doloroso, ou não. Assim, para ela, a castração de gatos provavelmente seria proibida com o fundamento de que ela impede, mesmo se feita de uma forma indolor e sem causar dor posterior, 0 florescimento (desenvolvimento) do gato na sua maneira característica de ser, privando-o da reprodução.

\section{Sentidos, imaginação e pensamento}

O desenvolvimento das capacidades, nesse caso, é o direito de os humanos serem capazes de usar os sentidos de imaginar, pensar e raciocinar e fazer essas coisas de um modo "verdadeiramente humano", o que exige educação adequada, liberdade de crença e pensamento, acesso à literatura, música, e assim por diante, garantindo-se, aos humanos, experiências agradáveis e não dolorosas. Para os 
seres humanos, segundo Nussbaum, essa capacidade leva-nos a pensar a relação com os não-humanos de forma que eles tenham leis proibindo o tratamento duro, cruel e abusivo, garantindo ao animal o acesso às fontes de prazer, tais quais a livre circulação em um ambiente que estimule e agrade os seus sentidos. Para a autora, não há, em relação aos não-humanos, caráter análogo à liberdade e à autonomia dos humanos, mas é possível pensar na autonomia prática de Steven Wise ${ }^{19}$.

\section{Emoções}

Esse é um direito comum a humanos e não-humanos. Trata-se de garantir que os seres possam ter ligações com as coisas e as pessoas, desenvolver seus afetos, cuidado e compaixão e não ter um desenvolvimento emocional marcado pelo medo e ansiedade.

\section{Razão Prática}

Aos humanos deve ser garantido o direito de ser capaz de formar uma concepção própria de bem e iniciar a reflexão crítica sobre a planificação da sua própria vida, o que implica a proteção da liberdade de consciência e de prática religiosa. No caso dos não-humanos, deve-se perguntar em que medida a criatura tem capacidade para enquadrar metas e projetos e planejar a sua vida. Sempre que essa capacidade estiver presente, ela deverá ser apoiada por critérios fundados no princípio da igualdade.

\section{A socialização}

A socialização é tanto a alteridade, presente na capacidade de viver com e para outros, de reconhecer e demonstrar respeito, de ser capaz de imaginar a situação de outro, quanto a base social da auto-estima, não humilhação e discriminação. No caso humano, para Nussbaum, a socialização tem duas faces: uma, interpessoal, outra, pública, focada no auto-respeito e não humilhação. Para ela, as duas faces da socialização são pertinentes para os animais não-humanos.

\footnotetext{
${ }^{19}$ Nussbaum não faz referência explicita a Wise (2002), mas estão presentes, em seu argumento, elementos do conceito de "autonomia prática".
} 
Isso porque eles também têm o direito à oportunidade de formar relacionamentos e de empenhar-se nas formas características de vinculação e inter-relacionamento gratificantes, recíprocos e não tirânicos.

\section{Outras espécies}

É direito dos seres humanos desenvolverem a capacidade de se preocupar com os animais e de viver em relação com eles, com as plantas e o mundo da natureza. Se os seres humanos têm direito a tudo isso, para Nussbaum, o mesmo acontece com os outros animais, em relação às espécies que não a sua própria, incluindo a humana, e o resto do mundo natural. Essa capacidade, vista a partir de ambos os lados, do animal e do humano, convida para a formação gradual de um mundo interdependente em que todas as espécies desfrutarão da cooperação e de relações de apoio mútuo. Mas, como a cooperação não é característica da natureza, a autora propõe a suplantação gradual do natural pelo justo.

\section{Interações lúdicas}

O direito humano de brincar e de desfrutar de atividades recreativas também se estende aos não-humanos, por ser uma atividade fundamental à vida de todo animal sensível.

\section{Controle sobre o próprio ambiente}

Para Nussbaum, esse controle pode ser "político", ou seja, que os humanos sejam capazes de participar efetivamente em uma das escolhas políticas que governam suas vidas, e "material". O controle "político", em outras palavras, é definido em termos de cidadania ativa e de direitos de participação política. $O$ "material", por sua vez, é definido em termos de garantia de igualdade nas mais diversas esferas da vida. Para animais não-humanos, a autora afirma que o importante é ser parte de uma concepção política que está estruturada de forma a respeitá-los e que se comprometa a tratá-los com justiça.

Nussbaum, ao final da sua lista, destaca que os conflitos entre os interesses de um e outro ser vivo são inevitáveis. Nessa hipótese, ela propõe o bem-estarismo 
como critério para resolver tais conflitos. Em sua lista não há uma proposta efetiva de hierarquia de princípios ou de princípios prima facie de mesma relevância. Ela não apresenta ou indica princípios que possam orientar a supressão, por exemplo, do que seria o direito ao bem-estar provocado pelo prazer hedonista do consumo de carne, frente ao direito à vida de outro ser; tampouco informa princípios que condenem ou exijam a busca de alternativas ao uso de um ser vivo em experimentos científicos. É possível afirmar que Nussbaum defende, em princípio, uma posição bem-estarista como alternativa aceitável. Não há em seu texto uma argumentação direta abolicionista em favor do direito dos animais não serem usados como meios para fins humanos.

O bem-estarismo de Nussbaum exige, porém, que se observe alguns pontos: a) o questionamento da relevância e da necessidade de uma determinada prática ou prática científica; b) o uso de animais sensíveis menos complexos; c) a melhoria das condições de vida dos não-humanos, por exemplo, o emprego do uso de cuidados paliativos no caso de doenças terminais adquiridas pelos experimentos; d) a remoção da brutalidade psicológica nos experimentos; e) a escolha, com cautela e prioridade, dos tópicos para que nenhum não-humano seja prejudicado por motivo fútil e, por fim, f) o desenvolvimento de métodos experimentais substitutivos, como a simulação em computadores. Além dessas orientações, a autora destaca que é necessária uma constante discussão pública sobre esse tema, de forma a evidenciar que o uso de animais é um fato trágico e de violação de direitos fundamentais. Para ela, os esclarecimentos públicos alertam para o que é moralmente certo.

Para se obter uma verdadeira justiça, é preciso olhar para além da espécie, olhar o mundo de forma a incluir todos os seres sencientes, "cujas vidas estão íntima e complexamente interligadas às nossas próprias" (NUSSBAUM, 2004, p. 318). Ao que parece é que a proposta de Nussbaum é uma ferramenta interessante de ser utilizada. O desafio está em garantir o desenvolvimento das capacidades de humanos e não-humanos sem reforçar perspectivas antropocêntricas e androcêntricas.

\section{Observações finais}

A discussão da proteção aos animais não-humanos circula por vários campos teóricos e teorias de justiça. De forma simplificada podemos pensar em duas 
perspectivas principais: a que opera construindo um discurso de direitos. Tornando, assim, os animais não-humanos como sujeitos de direitos subjetivos. E a perspectiva que observa que os direitos em si não são relevantes, mas, a construção de uma lógica de igual consideração de interesses semelhantes na qual estará nas mãos de quem tem poder de ação o dever de cuidado e de não fazer mal.

Martha Nussbaum constrói sua teoria a partir da lógica jurídica, mas inova. Traz para o campo da filosofia a teoria do desenvolvimento das capacidades fazendo, assim, com que a liberdade seja, mesmo para animais não-humanos, o objeto principal de valor. Liberdade aqui como a possibilidade legítima e legal de desenvolver suas capacidades. Assim, respeitar a natureza, permitir ser quem somos, é a pedra angular do postulado proposto por ela.

Ela busca ir além da abordagem antropocêntrica do desenvolvimento das capacidades, estendendo-a para não-humanos. Com isso, ela espera ter uma série de princípios políticos, básicos e mapeados, que venham a orientar a legislação e a política pública voltadas para humanos e não-humanos. A autora desenvolve, assim, uma lista na qual conceitua as capacidades humanas que considera centrais, e desenvolve um parâmetro para os não-humanos.

O ponto controverso de sua teoria está quando a autora afirmar que as diferentes formas de vida, que têm capacidades mais complexas a serem prejudicadas, tendem a sofrer mais e sofrer diferentemente os danos. Nesse momento ela cria uma espécie de hierarquia especista e permite até argumentos em prol do bem-estarismo. Isso porque os exemplos trazidos por ela operam a partir de uma lógica antropocêntrica, mesmo quando ela diz tentar evitá-la.

Mas é fato que Nussbaum traz uma nova lupa para pensar um tema delicado, complexo e fundamental. Se o futuro reserva espaço para a coerência e práticas verdadeiramente abolicionistas não sabemos, porém, cabe aos pensadores de agora o dever de reinventar suas próprias teorias de forma que justiça não se confunda com pleonexia. 


\title{
"CAPACITY": THE POSTULATE TO ENLARGE THE LEGAL AND MORAL COMMUNITY ACCORDING TO MARTHA NUSSBAUM'S PROPOSAL
}

\begin{abstract}
:
Who are the members of a moral community and why? You can answer this question in various ways and these ways will browse through different theoretical conceptions. Capacity building was used by authors such as Amartya Sen and Martha Nussbaum in order to substantiate assumptions as liberty and equality. On this track, Nussbaum uses the same logic to think the relationship between humans and nonhumans. The discussion concerning non-human animal protection, from its recognition as subjects of rights until their respect duty, meets different theories in practical ethics. This article analyses Martha Nussbaum's proposal whose work with the argument of capacity development gives the foundation to the recognition of the duty of respect to non-human animals as subjects of rights.
\end{abstract}

Keywords: Nussbaum. Non-human Animals. Development of Capacity.

\section{"CAPACIDADES": COMO POSTULADO PARA AMPLIAR LA COMUNIDAD JURÍDICA Y MORAL EN LA PROPUESTA DE MARTHA NUSSBAUM}

\section{Resumen:}

¿Quiénes son los miembros de una comunidad moral y por qué? Es posible responder a esta pregunta de diversas maneras y estas maneras representan diferentes concepciones teóricas. El desarrollo de capacidades fue utilizado por autores como Amartya Sen y Martha Nussbaum con el fin de fundamentar presupuestos como la libertad y la igualdad. En esa dirección, Nussbaum utiliza la misma lógica para pensar la relación entre humanos y no humanos. El debate sobre la protección de los animales no humanos, desde su reconocimiento como sujetos de derechos hasta la obligación de respeto, se depara con diferentes teorías en la ética práctica. En este artículo se analiza la propuesta de Martha Nussbaum, cuyo argumento de desarrollo de las capacidades justifica el reconocimiento de la obligación de respetar y reconocer a los animales no humanos como sujetos de derechos.

Palabras-clave: Nussbaum. Animales no humanos. Desarrollo de las capacidades. 


\section{Referências}

ABBAGNANO, Nicola. DICCIONARIO DE FILOSOFIA. Actualizado y aumentado por Giovanni Fornero. Tradução de José Esteban Calderón, Alfredo N. Galleti, Eliane Cazenave Tapie Isoard, Beatriz González Casanova, Juan Carlos Rodríguez. 4. ed. México: FCE, 2004.

BENTHAM, Jeremy. Uma introdução aos princípios da moral e da legislação. Tradução João Marcos Coelho. 3.ed. São Paulo: Abril Cultural, 1984. (Coleção Os Pensadores).

BUGLIONE, Samantha. Esterilização de mulheres: desenvolvimento, preservação de recursos naturais e respeito à autonomia. In: BUGLIONE, Samantha; VENTURA, Miriam (Orgs). Direito à Reprodução e à Sexualidade: uma questão de ética e justiça. Rio de Janeiro: Lumen Juris, 2010.

CHIOVENDA, Giuseppe. Instituições de direito processual civil. v. I. Tradução J. Guimarães Menegale. 2. ed. São Paulo: Saraiva, 1965.

FELIPE, Sônia T. Valor inerente e vulnerabilidade: critérios éticos não-especistas na perspectiva de Tom Regan. In: ETHIC@, Florianópolis, v. 5, n. 3, p. 125-146, jul. 2006.

FELIPE, Sonia. Ética Biocêntrica: tentativa de Superação do Antropocentrismo e do Sencientismo Ético. In: ETHIC@. Florianópolis, v. 7, n. 3, p. 1- 7, dez. 2008.

HARE, Richard. Moral Thinking: its Levels, Method and point. Oxford: Clarendon Press, 1981.

KANT, Emanuel. Resposta à pergunta: O que é o esclarecimento. In: KANT, Emanuel. À paz perpétua e outros opúsculos. Tradução Arthur Morão. Lisboa: Edições 70, 1995.

KELSEN, Hans. Teoria Pura do Direito. Tradução João Baptista Machado. 6. ed. São Paulo: Martins Fontes, 1998.

LALANDE, André. Vocabulário técnico e crítico de Filosofia. Tradução Fátima Sá Correia, Maria Emília V. Aguiar, José Eduardo Torres, Maria Gorete de Souza. São Paulo: Martins Fontes, 1999. 
LAZZARATO, Maurízio. Del Biopoder a la Biopolítica. In: Multitudes, mar. 2000. Disponível em: http://multitudes.samizdat.net/spip.php?article298. Acesso em: 26 fev. 2009. $\mathrm{P}$ 1-6.

NUSSBAUM, Martha. Beyond "compassion and humanity": Justice for Nonhuman Animals. In: . Animal Rights: Current Debates and New Direction. Oxford, 2004.

POPPER, Karl. Ciência: conjecturas e refutações. In: . Conjecturas e

Refutações. Brasília: UnB, 1982.

REGAN, Tom. Jaulas Vazias: encarando o desafio dos direitos dos animais. Trad. Regina Rheda. Revisão técnica Sônia T. Felipe e Rita Paixão. Porto Alegre: Lugano, 2006.

SEN, Amartya. Desenvolvimento como Liberdade. Tradução Laura Teixeira Motta. São Paulo: Companhia das Letras, 2000.

SINGER, Peter. Ética Prática. Tradução Jefferson Luiz Camargo. 3. ed. São Paulo: Martins Fontes, 2002.

SINGER, Peter. Libertação Animal. Tradução Marly Winckler. Porto Alegre: Lugano: 2004.

TAYLOR, Paul. Respect for Nature: a Theory of Environmental Ethics. $2^{\mathrm{a}}$. impressão. New Jersey, Princeton: Princenton University Press, 1987.

WISE, Steven. Drawing the Line: Science and the Case for Animal Rights.

Cambridge MA: Perseus Publishing, 2002.

Artigo:

Recebido em: Outubro/2012 Aceito em: Maio/2013 